\title{
- Aspectos clínicos e morfológicos das alterações prostáticas em cães - 1evisão
}

\section{- A review of clinical and morphological aspects of prostate alterations in dogs}

\author{
Giovana Wingeter Di Santis ${ }^{1}$ - CRMV -SP - $n^{0} 11958$ \\ Renée Laufer Amorim² ${ }^{2}$ - CRMV-SP-n ${ }^{0} 8303$ \\ * Enio Pedone Bandarra ${ }^{3}$-CRMV-SP-n'0786
}

*Faculdade de Medicina Veterinária e Zootecnia UNESP

Laboratório de Patologia e Medicina Legal Veterinária

Departamento de Clínica Veterinária CEP 18618-000 - Botucatu - SP Fone: $\left(0^{\star \star} 14\right) 6802-6293$ End. Eletrôn.: bandarraep@fmvz.unesp.br

1 Mestranda em Medicina Veterinária - FMVZ - UNESP / Botucatu/SP.

2 Doutoranda em Medicina Veterinária - FMVZ - UNESP / Botucatu/SP.

3 Professor Adjunto do Departamento de Clínica Veterinária - FMVZ - UNESP / Botucatu/SP.

\section{RESUMO}

O presente trabalho tem por objetivo apresentar uma revisão sobre as principais afecções que podem acometer a próstata de cães, tendo em vista a necessidade deste conhecimento por todos que militam na área de pequenos animais. A literatura humana tem referido o cão como modelo experimental no estudo de lesões prostáticas, especialmente no que diz respeito a hiperplasia prostática benigna (HPB) e ao carcinoma prostático. Tais estudos objetivam maior rapidez e eficácia no diagnóstico e novas alternativas terapêuticas para estas afecções, uma vez que, a exemplo do que ocorre com a espécie humana, a geriatria veterinária tem ganho destaque substancial nos últimos anos. As afecções prostáticas são problemas comuns em cães adultos e idosos e estão associadas principalmente ao avanço da idade e desequilíbrio hormonal. As mais freqüentes são prostatites, hiperplasias prostáticas benignas (HPB) e carcinomas, além de cistos, abscessos e metaplasias escamosas que geralmente ocorrem em conseqüência aos processos inicialmente citados. Devido à similaridade dos sinais clínicos decorrentes destas moléstias, o diagnóstico deve basear-se em um conjunto de informações provenientes do exame clínico dos animais associadas à exames laboratoriais e técnicas de diagnóstico por imagens.

Palavras-chave: cão, próstata, prostatite, hiperplasia prostática benigna, carcinoma prostático.

\section{Introdução}

próstata, a única glândula sexual acessória do cão, é um órgão bilobulado com septo mediano na superfície dorsal e está localizada caudalmente à bexiga, junto ao seu colo (BARSANTI e FINCO, 1992). Apresenta-se ventralmente ao reto e dorsalmente à sínfise púbica e envolve completamente a uretra proximal (OLSON et al., 1987).
A localização da próstata pode variar em função da distensão da bexiga e de possíveis alterações neste órgão. Com o avanço da idade, a próstata tende a aumentar gradualmente de volume, como resultado da hiperplasia glandular, e desloca-se cranialmente, de forma que a maioria dos machos não castrados, com mais de cinco anos de idade, apresentam a maior porção dessa glândula em posição abdominal. A distensão exagerada da bexiga pode também tracionar a próstata para a cavi- 
DI SANTIS, G. W.; AMORIM, R. L.; BANDARRA, E. P. Aspectos clínicos e morfológicos das alterações prostáticas em cães - revisão / A review of clinical and morphological aspects of prostate alterations in dogs. / Rev. educ. contin. CRMV-SP / Continuous Education Journal CRMV-SP, São Paulo, volume 4, fascículo 2, p. 46 - 52, 2001.

dade abdominal (BARSANTI e FINCO, 1992; DORFMAN e BARSANTI, 1995).

A função da próstata é produzir um fluido que forneça o ambiente propício para a sobrevivência e motilidade dos espermatozóides durante a ejaculação. Este Tabela 1. Sinais clínicos associados às moléstias prostáticas.

\begin{tabular}{|c|c|c|c|}
\hline Corrimento uretral & Febre, dor, depressão & Disúria & Tenesmo \\
\hline Neoplasia & Neoplasia & Neoplasia & Neoplasia \\
\hline Abscesso & Abscesso & Abscesso & Abscesso \\
\hline Cisto & - & Cisto & Cisto \\
\hline Prostatite bacteriana & Prostatite Bacteriana aguda & - & - \\
\hline- & - & - & Hiperplasia \\
\hline
\end{tabular}
fluido é produzido sob estímulo parassimpático do nervo pélvico e eliminado durante a ejaculação por estímulo simpático do nervo hipogástrico. Pequenas quantidades de fluido prostático são secretadas constantemente e, se não ocorrer micção ou ejaculação, a pressão uretral o conduz para o interior da bexiga (BARSANTI e FINCO, 1992).

Histologicamente, a próstata canina é composta por ácinos túbulo-alveolares que se estendem-se até a sua abertura no ducto uretral e são sustentados por um estroma de tecido conjuntivo e músculo liso, envoltos por uma espessa cápsula fibromuscular. As células glandulares são desde cúbicas até colunares e apresentam-se normalmente em dupla camada: epitélio secretor e epitélio basal, este último localizado ao longo da membrana basal. Nos ductos excretórios que se abrem no interior da uretra, o epitélio torna-se do tipo transicional. O estroma consiste de fibroblastos e células musculares lisas envolvidos em colágeno, com vasos sanguíneos e nervos (OLSON et al., 1987; BARSANTI e FINCO, 1992; DORFMAN e BARSANTI, 1995).

No cão, o crescimento prostático e suas alterações morfológicas relacionadas à idade vêm sendo cada vez mais estudados em razão da similaridade de ocorrência entre a hiperplasia prostática benigna (HPB) do cão e do homem (DORFMAN e BARSANTI, 1995). Além disso, é a única espécie não humana na qual o câncer prostático ocorre espontaneamente com grande freqüência (WATERS et al., 1997).

Doenças prostáticas são problemas comuns em cães adultos e idosos. As mais freqüentes são as prostatites bacterianas, cistos prostáticos, hiperplasias prostáticas benignas, carcinomas e abcessos (KRAWIEC, 1994). Cães sexualmente intactos têm maior probabilidade de desenvolvê-las que os castrados, entretanto as neoplasias ocorrem nos dois grupos com incidência semelhante, indicando que a castração não confere proteção em relação a essa afecção (KRAWIEC e HEFLIN, 1992).

Os sinais clínicos relacionados à doença prostática em cães variam com o tipo e a gravidade da lesão (Tabela 1) e graças à grande semelhança entre eles, o diagnós-

tico torna-se um constante desafio (BARSANTI e FINCO, 1992; MUZZI et al., 1999).

\section{Cistos prostáticos}

Podem ser únicos ou múltiplos e são classificados de acordo com sua etiologia. Os de ocorrência mais comum, segundo OLSON et al. (1987); KRAWIEC (1994); DORFMAN e BARSANTI (1995), são:

Congênitos: geralmente localizados na base da bexiga com comprometimento da superfície prostática; são pouco freqüentes e acredita-se serem vestígios embrionários dos ductos müllerianos;

Cistos associados à metaplasia escamosa: 0 lúmen glandular apresenta-se repleto de ceratina, levando a obstruções. Usualmente estão relacionados ao hiperestrogenismo;

Cistos de retenção: formam-se a partir da obstrução de ductos excretores com posterior retenção do material secretado pelas células epiteliais;

Cistos associados à HPB: são indubitavelmente os mais freqüentes, relacionados à hiperplasia e ao aumento na secreção das células acinares. (Figuras 1 e 2).

\section{Prostatite}

A prostatite é uma afecção muito comum em cães, principalmente adultos e idosos, estando associada com freqüência à HPB. Pode ser aguda ou crônica e distribui-se de forma focal ou difusa (JUBB et al., 1993; JONES et al., 2000).

Em um estudo com 177 cães portadores de doença prostática, KRAWIEC e HEFLIN (1992) observaram prostatite em 33 casos $(18,6 \%)$ sendo o processo de maior incidência.

A etiologia desta inflamação envolve bactérias gram positivas e gram negativas, das quais a Escherichia coli é o agente mais freqüente, seguida por Staphylococcus aureus, Klebsiella spp., Proteus mirabilis, Mycoplasma canis, Pseudomonas aeruginosa, En- 


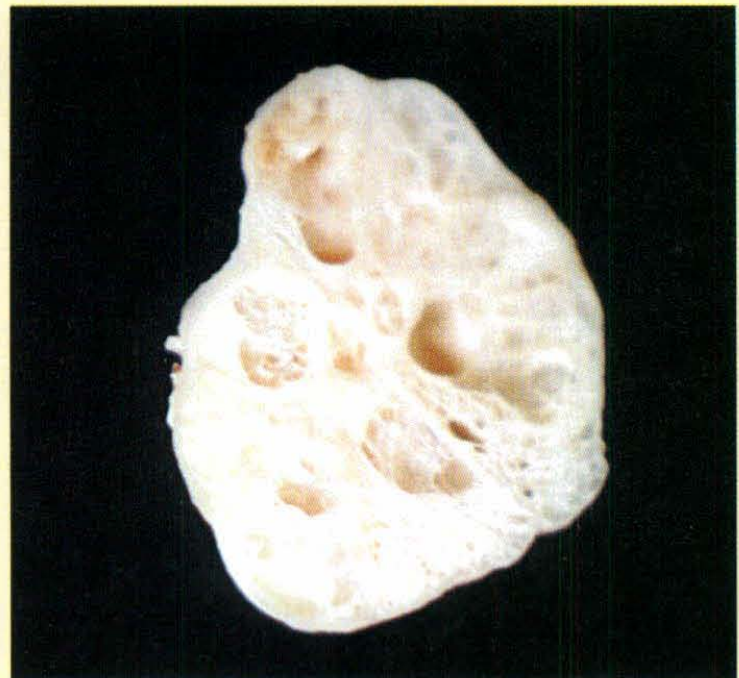

Figura 1: Hiperplasia Prostática Benigna. Superfície de corte de um lobo prostático. Presença de inúmeros cistos de tamanho variado.

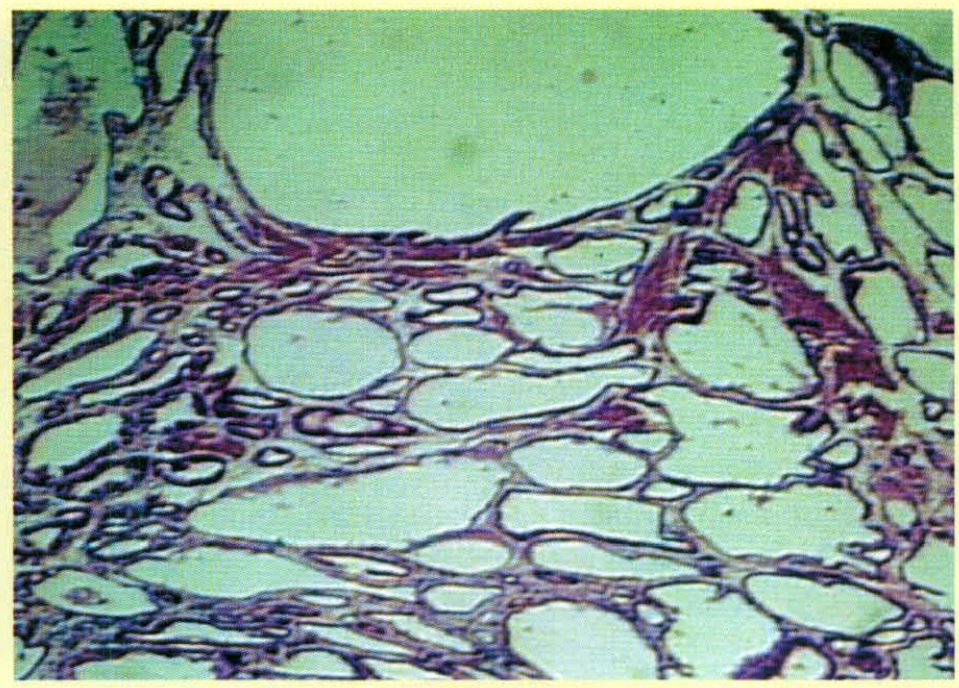

Figura 2: Hiperplasia Prostática Benigna. Dilatações císticas das glândulas. H.E., $100 \mathrm{x}$ terobacter spp., Streptococcus spp., Pasteurella spp. e Haemophilus spp. A Brucella canis também pode infectar a próstata canina embora esteja associada, com maior frequiência, as infecções dos testículos e epidídimos. A via de contaminação mais comum é a ascendente, porém a hematógena e a disseminação focal de infecções da bexiga e rins podem ocorrer (DORFMAN e BARSANTI, 1995; JOHNSTON et al., 2000; JONES et al., 2000).

A migração bacteriana para o interior da próstata é geralmente inibida por mecanismos de defesa não específicos como o fluxo urinário durante a micção, a alta pressão da zona uretral, os efeitos bactericidas do fluido prostático e a produção local de imunoglobulina A. O flu-

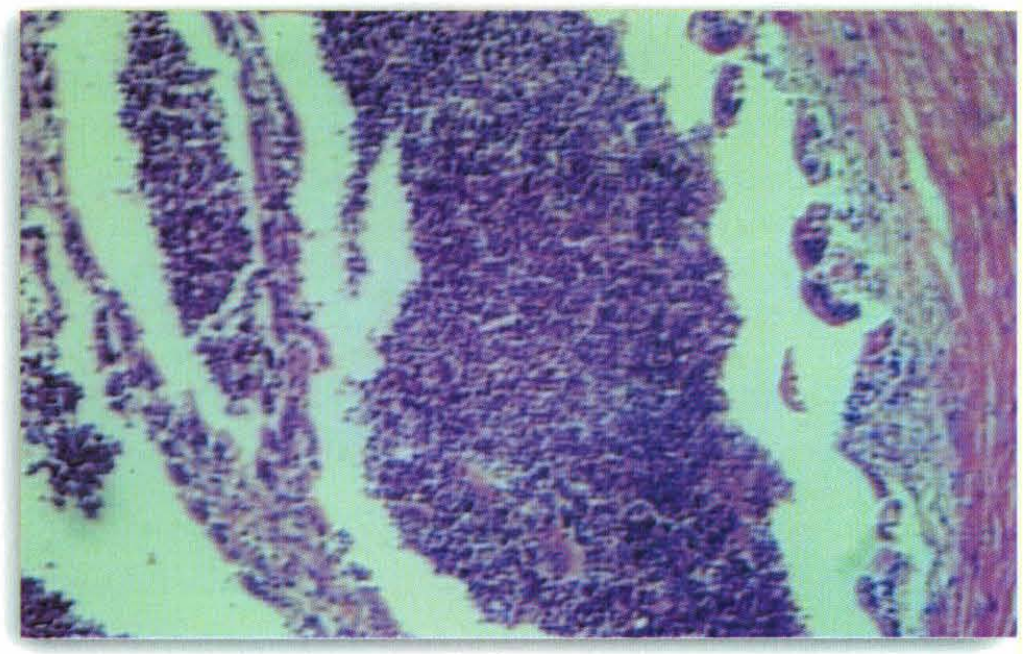

Figura 3: Prostatite Aguda (supurativa). Lúmen glandular repleto de exsudato purulento. H.E., 200x. xo urinário e a produção de imunoglobulina inibem a aderência desses agentes no urotélio e então previnem a colonização bacteriana na próstata. No entanto, qualquer condição que aumente o número de bactérias na uretra prostática (infecções do trato urinário inferior, urolitíases, neoplasias, traumas) ou que altere a secreção normal de fluido prostático (metaplasia escamosa, hiperplasia cística) funciona como fator predisponente à infecção (DORFMAN e BARSANTI, 1995).

\section{Prostatite aguda}

É uma inflamação difusa ou focal, supurativa, com tendência à formação de abcessos que podem romper, ocasionando peritonite, septicemia e morte. Geralmente está acompanhada de manifestações sistêmicas da doença, e cerca de dois terços dos cães afetados apresentam sinais clínicos no trato urinário, como hematúria ou piúria, secreção uretral, incontinência urinária e disúria. Dependendo de sua duração, pode comprometer os ácinos ou estender-se ao estroma. Caracteriza-se microscopicamente por exsudato purulento no interior do lúmen glandular, podendo haver infiltração de linfócitos, plasmócitos e macrófagos no estroma (JUBB et al., 1993; JONES et al., 2000) (Figura 3).

\section{Prostatite crônica}

Pode ser uma conseqüência do processo agudo ou surgir de forma insidiosa. Geralmente está 
DI SANTIS, G. W.; AMORIM, R. L.; BANDARRA, E. P. Aspectos clínicos e morfológicos das alterações prostáticas em cães - revisão / A review of clinical and morphological aspects of prostate alterations in dogs. / Rev. educ. contin. CRMV-SP / Continuous Education Journal CRMV-SP, São Paulo, volume 4, fascículo 2, p. 46 - 52, 2001.

associada a infecções do trato urinário, urolitíases, cistos, neoplasias ou metaplasia escamosa. Na maioria das vezes, não se observam sinais sistêmicos da doença mas secreção uretral geralmente está presente. A próstata afetada, freqüentemente está aumentada, mas pode não apresentar alterações macroscópicas. Microscopicamente, os ácinos tendem a estar atróficos e focos de metaplasia escamosa algumas vezes estão presentes. O lúmen glandular contém variável quantidade de macrófagos, debris celulares e neutrófilos, e o estroma adjacente, quase sempre, apresenta agregados de linfócitos e plasmócitos. Ainda, a criptococose e a blastomicose podem causar um tipo especial de prostatite crônica em cães: a prostatite granulomatosa (BARSANTI e FINCO, 1992; JUBB et al., 1993; KRAWIEC, 1994; DORFMAN e BARSANTI, 1995).

\section{Hiperplasia Prostática Benigna (HPB)}

Há controvérsias na literatura veterinária no que se refere à ocorrência de hiperplasia ou hipertrofia na próstata canina; no entanto, há relatos que sugerem que ambas estão presentes (OLSON et al., 1987).

A HPB ocorre com alta incidência no cão e no homem e está associada ao avanço da idade e ao desequilíbrio hormonal, em que a testosterona (T4), a dehidrotestosterona (DHT) e o estrogênio têm papel decisivo (LOWSETH et al., 1990; DORFMAN e BARSANTI, 1995; MURAKOSHI et al., 1998).

A DHT é um catabólito da testosterona circulante, sintetizado na próstata pela ação da enzima 5-a redutase tipo 2. Essa enzima está localizada principalmente nas células estromais, podendo atuar nelas, de forma autócrina, ou nas células epiteliais glandulares, de forma parácrina. Em ambas, a DHT liga-se a receptores androgênicos nucleares, que sinalizam a transcrição de fatores de crescimento para as células epiteliais e estromais. Da mesma forma, a testosterona pode ligar-se a receptores nucleares e estimular o crescimento celular, contudo a DHT é dez vezes mais potente por dissociar-se mais lentamente dos receptores (MURAKOSHI et al., 1998; COTRAN et al., 1999).

Os estrógenos favorecem o desenvolvimento da HPB, visto que promovem um aumento do número de receptores para andrógenos, alteram o metabolismo esteróide, aumentando a formação de DHT na próstata e estimulam o crescimento de músculo liso, assim como a síntese de colágeno estromal (EWING et al., 1983; POULET, 1985; BARTSCH et al., 1987; COTRAN et al., 1999).

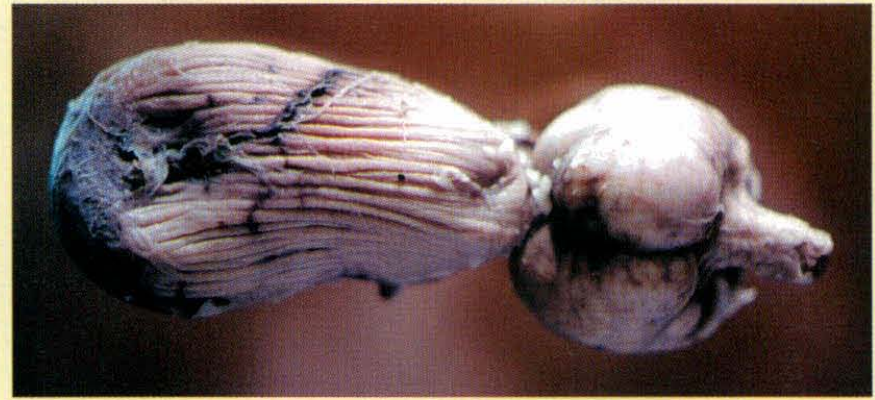

Figura 4. Hiperplasia Prostática Benigna. Aumento de volume prostático de aspecto nodular.

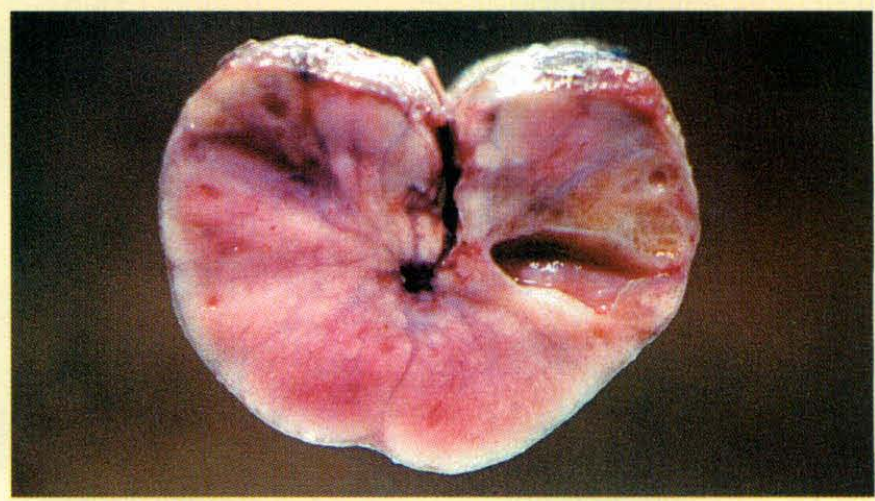

Figura 5. Hiperplasia Prostática Benigna. Superfície de corte mostrando cisto, pequenos nódulos de coloração esbranquiçada, correspondentes à áreas de hiperplasia estromal.

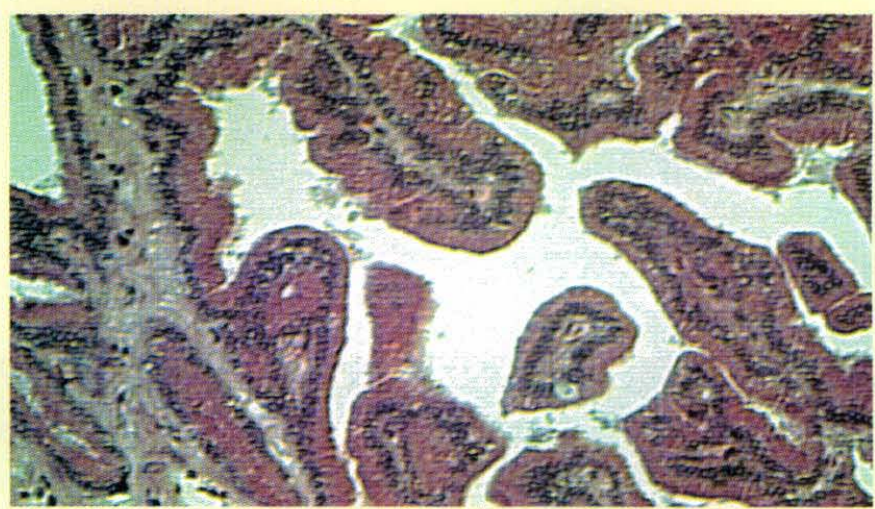

Figura 6. Hiperplasia Papilífera. Proliferação de células epiteliais projetando-se para o lúmen glandular. H.E., 400x.

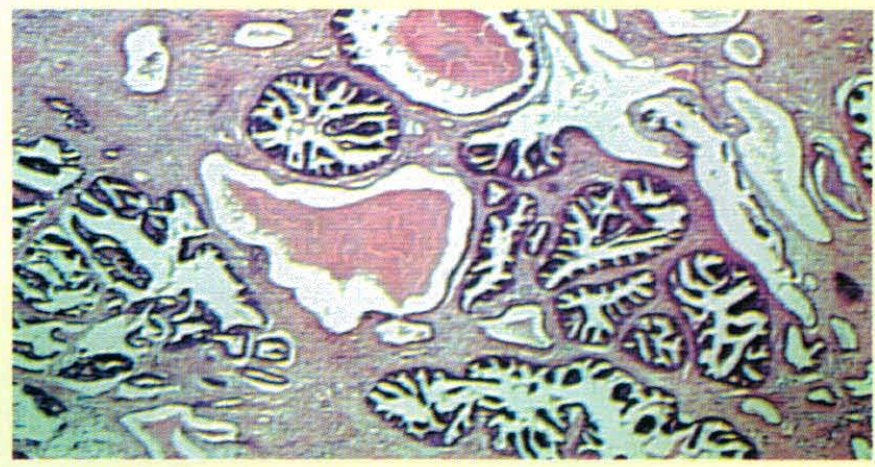

Figura 7. Hiperplasia Prostática Benigna. Hiperplasia cística, papilífera e estromal, com infiltrado inflamatório intersticial difuso. H.E., 100x. 
DI SANTIS, G. W.; AMORIM, R. L.; BANDARRA, E. P. Aspectos clínicos e morfológicos das alterações prostáticas em cães - revisão / A review of clinical and morphological aspects of prostate alterations in dogs. / Rev. educ. contin. CRMV-SP / Continuous Education Journal CRMV-SP, São Paulo, volume 4, fascículo 2, p. 46 - 52, 2001.

Em cães da raça Beagle, a HPB está presente em $40 \%$ dos animais com dois anos e meio de idade, em mais de $80 \%$ com idade superior a seis anos e em $95 \%$ daqueles com mais de nove anos (BARSANTI e FINCO, 1992). No homem, cerca de $20 \%$ dos indivíduos de quarenta anos, $70 \%$ dos de sessenta anos e $90 \%$ dos de setenta anos apresentam HPB (COTRAN et al., 1999).

Há importantes diferenças entre a HPB no cão e no homem. Segundo ISAACS (1984), no cão a HPB é difusa e envolve primariamente células epiteliais com menor envolvimento estromal, enquanto no homem é nodular, com envolvimento primário de elementos estromais. Outra diferença diz respeito a fatores anatômicos, pois no homem a próstata encontra-se fixada entre a sínfise púbica e o reto, e o crescimento hiperplásico ocorre internamente, sobre a uretra, produzindo obstrução urinária. No cão a próstata não é fixa, e o crescimento hiperplásico ocorre externamente, produzindo obstrução retal e constipação (LOWSETH et al., 1990). Por outro lado, a próstata do homem tem maior quantidade de músculo liso que a canina, principalmente na zona periuretral, e na presença de agentes a-1-agonistas é gerado um aumento na tensão muscular, levando à compressão uretral (LEPOR et al., 1992).

Invariavelmente, a próstata apresenta-se aumentada de volume (Figura 4), mas seu aspecto externo, assim como o da superfície de corte, irá variar de acordo com o padrão de hiperplasia presente (Figura 5). Microscopicamente pode-se observar hiperplasia epitelial dos tipos papilífera (Figura 6) e cística, ou estromal. É comum a observação desses processos concomitantemente (Figura 7).

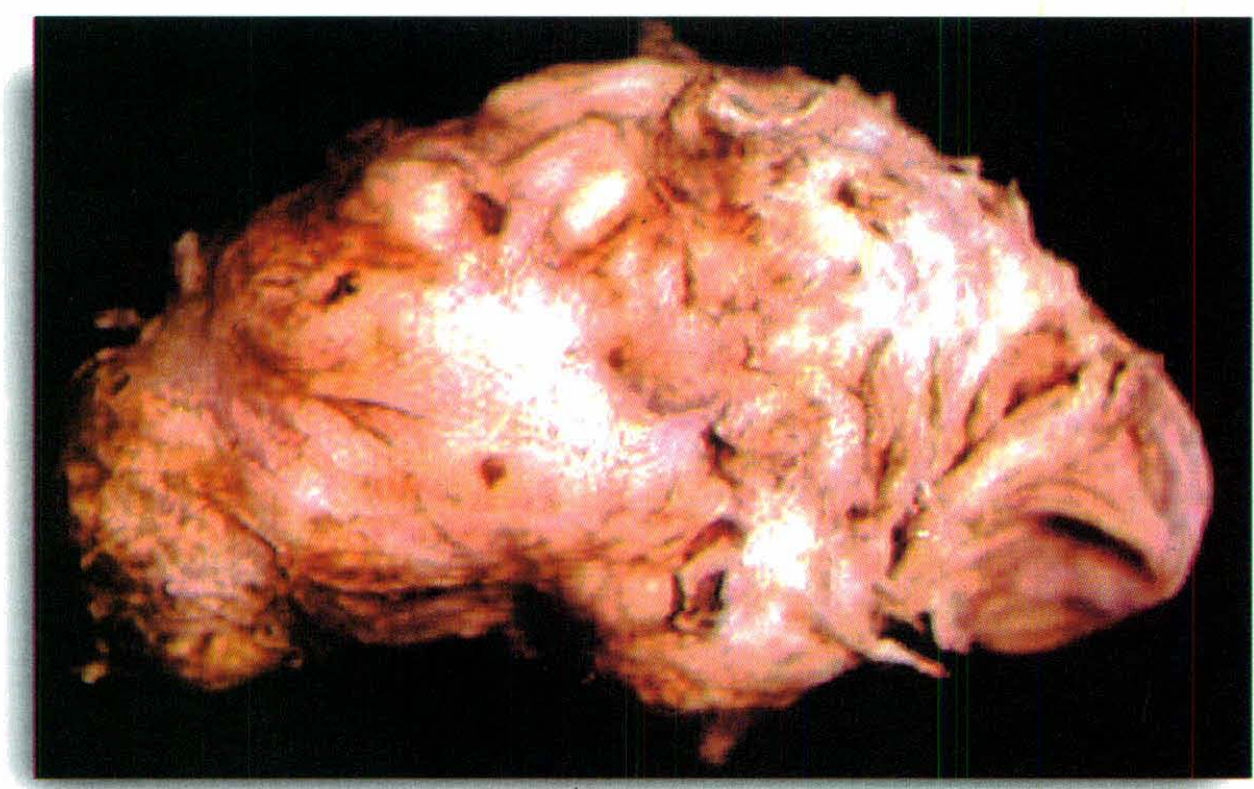

Figura 8. Carcinoma Prostático. Aumento de volume nodular com perda da arquitetura normal.

\section{Neoplasias}

As neoplasias primárias observadas na próstata canina são: adenocarcinoma, carcinoma de células de transição, carcinoma de células escamosas, leiomiossarcoma e fibrossarcoma. Neoplasias metastáticas não são comuns, mas o linfoma pode infiltrar-se na glândula (JUBB et al., 1993; JONES et al., 2000).

Os adenocarcinomas são os mais freqüentes com maior incidência em cães idosos (dez anos de idade, em média). Animais afetados podem apresentar emaciação e distúrbios locomotores dos membros posteriores. Metástases podem estar presentes em linfonodos ilíacos, pélvicos e lombares, em vértebras lombares, rins, bexiga, pulmão, coração, mesentério e epíploon (JUBB et al., 1993; DORFMAN e BARSANTI, 1995; JONES et al., 2000). Essas neoplasias não são consideradas uma evolução da HPB e, apesar da etiologia ser desconhecida, parece claro que desenvolvem-se em um ambiente de desequilíbrio hormonal, provavelmente com envolvimento de outros fatores (JUBB et al., 1993; JONES et al., 2000).

A próstata pode ou não apresentar aumento de volume, dependendo do grau de evolução da neoplasia, porém na maioria dos casos o diagnóstico é tardio, quando os sinais clínicos decorrentes do aumento glandular já estão presentes (Figura 8).

Segundo JUBB et al. (1993); JONES et al. (2000), a classificação histológica dos adenocarcinomas prostáticos divide-se em:

Carcinoma intra-acinar proliferativo: é o padrão mais comum. Observam-se múltiplos focos de alvéolos irregularmente formados que contém células neoplásicas ramificando-se de uma densa camada basal em direção ao lúmen acinar. Essas células não estão sobre uma membrana basal intacta e essa é uma característica importante para diferenciar esse processo da HPB;

Carcinoma de pequenos ácinos: os ácinos estão envoltos por uma excessiva proliferação estromal, são pequenos e torna-se necessária atenção especial ao pleomorfismo celular para diferenciar esse processo da atrofia glandular;

Carcinoma sincicial indiferenciado (sarcomatóide): composto por células pleomórficas, geralmente fusiformes e dispostas em lençol, lembrando um sarcoma. 
Tais células são entremeadas a ácinos neoplásicos;

Carcinoma de pequenas células: apresenta células pequenas, redondas a poligonais, em anel de sinete embebidas no estroma.

\section{Metaplasia escamosa}

É a transformação do epitélio glandular em epitélio escamoso estratificado, no qual a ceratina é depositada no interior do lúmen. Geralmente está associada à prostatite crônica, irritação crônica (cálculos) ou ao estímulo prolongado por estrógenos endógenos (tumor de células de Sertoli) ou exógenos. Em casos avançados, os ácinos transformam-se em massas sólidas e císticas de epitélio escamoso bem diferenciado (JUBB et al., 1993; JONES et al., 2000) (Figura 9).

\section{Métodos diagnósticos de lesões prostáticas}

A avaliação prostática é feita tradicionalmente pelo histórico, pela sintomatologia clínica e pela palpação retal, porém outras técnicas podem ser utilizadas, a fim de se obter um diagnóstico mais preciso e confiável. Entre elas, exames radiológicos, análise do fluido prostático, urinálise, avaliação bioquímica e hematológica e, na última década, ultra-sonografia. Esta técnica possibilitou a realização de citologia aspirativa e biopsia de forma mais eficaz e segura (OLSON et al., 1987; DORFMAN e BARSANTI, 1995; MUZZI et al., 1999).

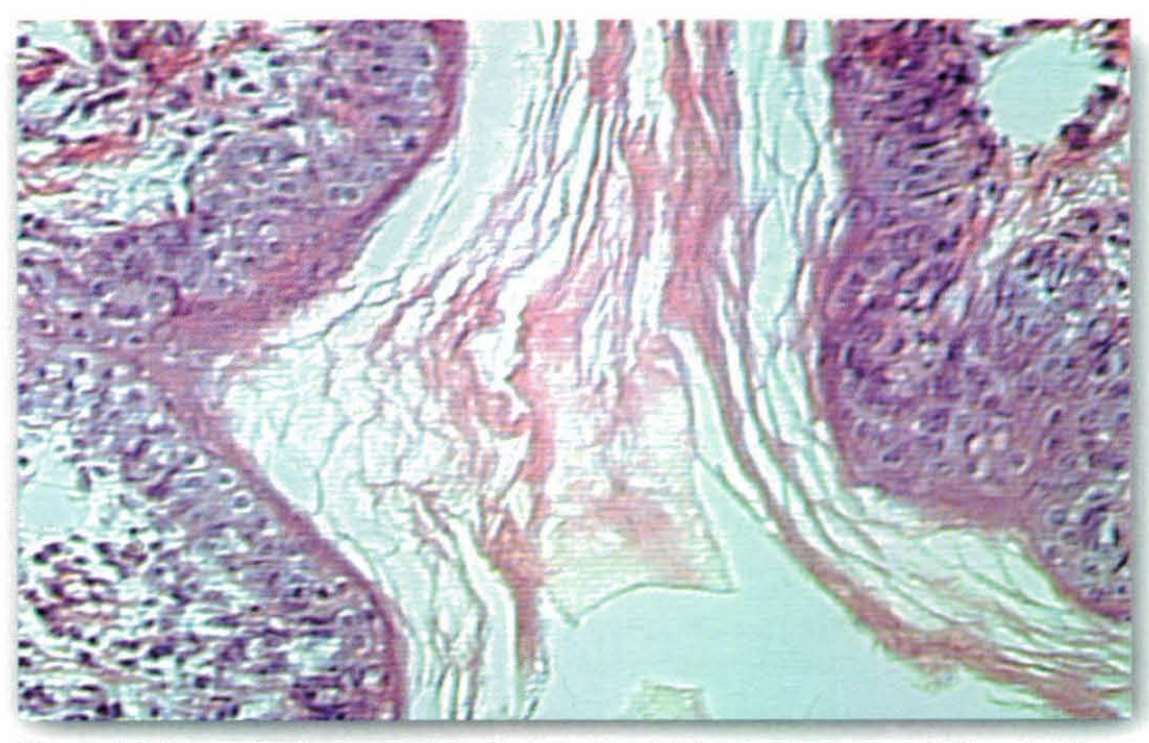

Figura 9. Metaplasia Escamosa. Substituição do epitélio glandular por epitélio estratificado escamoso bem diferenciado com ceratina no lúmen acinar. H.E., 400x.

A diferenciação entre processos proliferativos, de natureza benigna ou maligna, em que a caracterização morfológica das células torna-se difícil, pode ser auxiliada pela utilização da imunoistoquímica. A integridade da camada de células basais é importante critério na diferenciação dessas lesões, sendo de grande utilidade sua visualização pôr métodos imunoistoquímicos (CAVALCANTE e ALVES, 1999).

A avaliação quantitativa dos componentes celulares em uma amostra de tecido pode ser feita com segurança através da análise morfométrica de imagens, tornando-se um método adicional no diagnóstico histopatológico. Mesmo um pequeno fragmento, obtido por biopsia, fornece informações precisas sobre as proporções entre os componentes teciduais (WELLS et al., 1993).

\section{SUMMARY}

Keeping in mind the necessity for more knowledge in the subject area, this study reviews the main disorders that can affect the prostate of dogs as a contribution for small animal practitioners. The human literature refers to the dog as an experimental model in the study of prostatic lesions, especially for the benign prostatic hyperplasia (BPH) and prostatic carcinoma. The objective of these studies is to achieve more efficient and rapid diagnosis and new therapeutic alternatives for these disorders, mainly in veterinary geriatrics. This specialty has become more important in the last years, as also occurred in human medicine. Mainly associated with aging and hormone unbalance, prostate diseases are a common problem in adult and elderly dogs. The most frequent disorders are protatitis, benign prostatic hyperplasias (BPH) and carcinomas, which can often result in cysts, abscess and squamous metaplasia. Due to the similarity of clinical signs of these diseases, diagnosis should be based on information obtained by clinical exam of the animals, laboratory tests and image diagnosis.

Key words: dog, prostate, protatitis, benign prostatic hyperplasia, prostatic carcinoma. 


\section{REFERÊNCIAS}

1. BARSANTI, J. A.; FINCO, D. R. Moléstias prostáticas do cão. In: ETTINGER, S. J. Tratado de medicina interna veterinária. 3. ed. São Paulo: Manole, 1992. v. 4, p. 1941-1963.

2. BARTSCH, G. et al. Correlation of biochemical (receptors, endogenous, tissue hormones) and quantitative morphologic (stereologic) findings in normal and hyperplastic human prostates. Journal of Urology, v. 137, n. 3, p. 559-564, 1987.

3. CAVALCANTE, F. B. C.; ALVES, V. A. F. Tumores urológicos. In: ALVES, V. A. F. et al. Manual de imuno-histoquímica, São Paulo: Sociedade Brasileira de Patologia, 1999. p. 47-54.

4. COTRAN, R. S. et al. The male genital tract. In: . Pathologic basis of disease. 6. ed. Philadelphia: W. B. Saunders, 1999. p. 1025-1033.

5. DORFMAN, M.; BARSANTI, J. A. Diseases of the canine prostatic gland. The Compendium of Continuing Education, v. 17, n. 6 , p. $791-811,1995$.

6. EWING, L. L. et al. Dihydrotestosterone concentration of Beagles prostatic tissue: effect of age and hyperplasia. Endocrinology, v. 113, n. 6, p. 2004-2009, 1983.

7. ISAACS, J. T. Common characteristics of human and canine benign prostatic hyperplasia. Progress in Clinical and Biological Research, v. 145, p. 217-234, 1984.

8. JOHNSTON, S. D. et al. Prostatic disorders in the dog. Animal Reproduction Science, v. 60-61, p. 405-415, 2000.

9. JONES T. C. et al. Sistema genital. In: ___. Patologia veterinária. 6.ed. São Paulo: Manole, 2000. p. 1237-1240.

10. JUBB, K. V. F. et al. Male genital system. In: Pathology of the domestic animals. 4. ed. San Diego: Academic Press, 1993. v. 3, p. 523-529.
11. KRAWIEC, D. R. Canine prostate disease. Journal of the American Veterinary Medical Association, v. 204, n. 10, p. 15611564, 1994.

12. KRAWIEC, D. R.; HEFLIN, D. Study of the prostatic disease in dogs: 177 cases (1981-1986). Journal of the American Veterinary Medical Association, v. 200, n. 8, p. 1119-1122, 1992.

13. LEPOR, H. et al. Binding and functional properties of alpha 1 adrenoceptors and area density of smooth muscle in the canine prostate. The Journal of Urology, v. 148, n. 4, p. 1310-1313, 1992.

14. LOWSETH, L. A. et al. Age-related in the prostate and testis of the Beagle dog. Veterinary Pathology, v. 27, n. 5, p. 347-353, 1990.

15. MURAKOSHI, M. et al. Immunolocalization of androgen receptor in canine prostatic hyperplasia. Tokai Journal Experimental Clinical Medicine, v. 23, n. 5, p. 209-212, 1998.

16. MUZZI, L. A. L. et al. Ultra-sonografia das afecções prostáticas em cães. Arquivos Brasileiros de Medicina Veterinária e Zootecnia, v. 51, n. 1, p. 9-16, 1999.

17. OLSON, P. N. et al. Disorders of the canine prostate gland: pathogenesis, diagnosis and medical theraphy. The Compendium of Continuing Education, v. 9, n. 6, p. 613-623, 1987.

18. POULET, F. Evolution de la prostate canine en fonction de l'âge. Annales Médecine Vétérinaire, v. 129, n. 8, p. 567-584, 1985.

19. WATERS, D. J. et al. Prostatic intraepithelial neoplasia in dogs with spontaneous prostate cancer. The Prostate, v. 30, n. 2, p. 92-97, 1997.

20. WELLS, W. A. et al. Equipment, standardization, and applications of image processing. Anatomical Pathology, v. 99, n. 1, p. $48-56,1993$

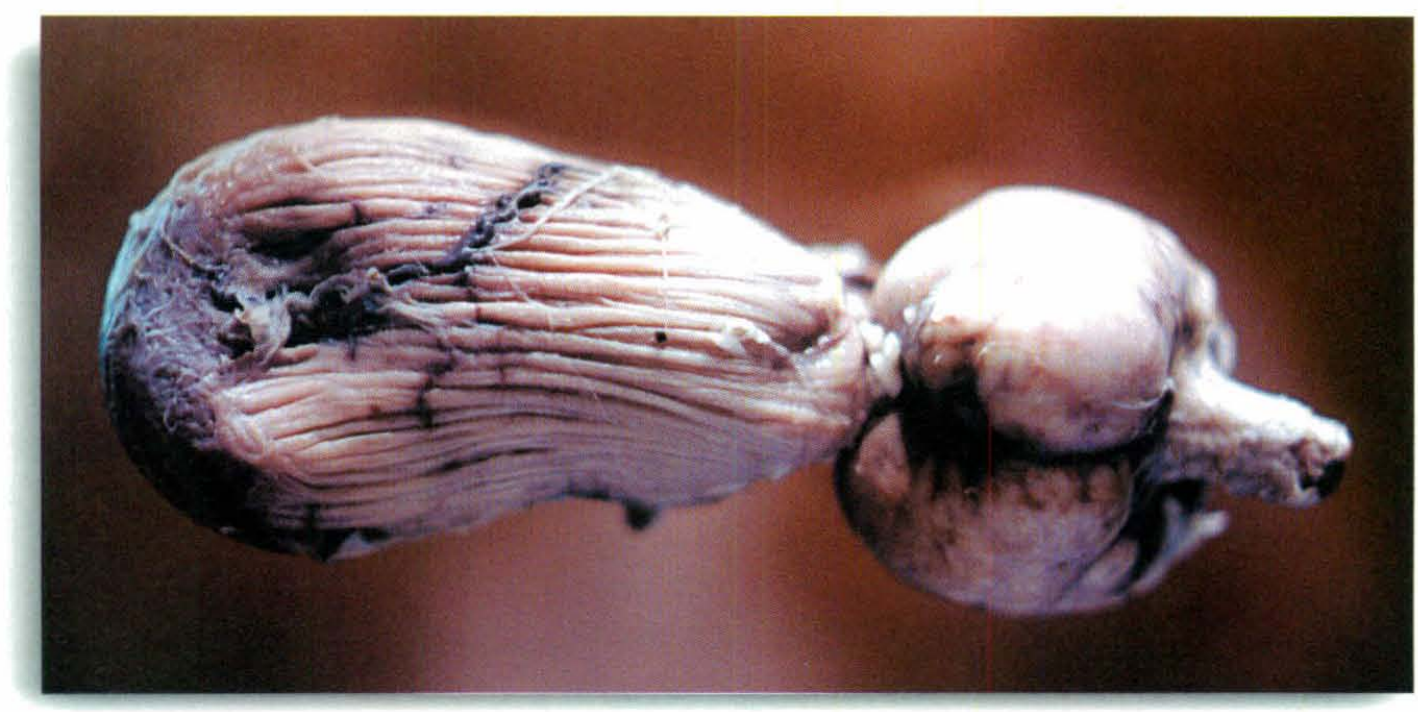

